\title{
Analisis Kelayakan Usaha Air Minum dalam Kemasan PT. Amiro di Desa Uma Jero, Kecamatan Busungbiu, Kabupaten Buleleng.
}

\author{
NI KETUT PURANI WIYANTI, \\ I WAYAN BUDIASA, I NYOMAN GEDE USTRIYANA \\ Program Studi Agribisnis Fakultas Pertanian Universitas Udayana \\ J1. PB. Sudirman Denpasar 80232 \\ Email: puraniwiyanti@gmail.com \\ wba.agr@unud.ac.id
}

\begin{abstract}
Analysis of Business Feasibility Study in Bottled Drinking Water of PT. Amiro in Uma Jero Village, Busungbiu District, Buleleng Regency.
\end{abstract}

Water is a major component in the human body, without which creatures cannot grow and develop. Drinking water is a major component of the body; on average each person has 70-80 percent of water from his body weight. The community has now switched from consuming ordinary drinking water which is cooked into bottled water. Companies engaged in the BDW sector keep increasing and continue to expand their product networks. The purpose of this study was to determine the bottled drinking water business at PT. Amirowhether it is financially feasible in terms of investment criteria, namely NPV, IRR, Net B / C, Payback Period and Sensitivity Analysis and the goal of the study was also to identify the constraints faced by PT. Amiro in running a business. Based on this research, it could be seen that the NPV value wasRp. 12,640,670,205, IRR $35.79 \%$, Net B / C 3.64, and the Payback Period was 8 years 3 months, therefore it means that BDW business of PT. Amirois financially feasible to be carried out. Constraints in the feasibility study of PT. Amiro, in developing the business process were that the licensing process took a lot of time to meet the requirements needed to obtain a business license such as the Agency of Food and Drug Control, Indonesian National Standard, Halal Certificate from MUI and ISO 9001. Amiro is a new player in the BDW business and is not yet known by the public so it needs a strategy to get market share from a very dense market.

Keywords : BDW, investment criteria, business feasibility

\section{Pendahuluan}

\subsection{Latar Belakang}

Air merupakan komponen utama dalam tubuh manusia, tanpa air makhluk hidup tidak dapat tumbuh dan berkembang karena air merupakan bahan dasar dari seluruh air tubuh termasuk darah dan enzim pencernaan (Hardinsyah, 2011). Air 
minum merupakan komponen utama dari tubuh, rata-rata setiap orang memiliki 70-80\% air dari berat tubuhnya. Semua sistem yang ada didalam tubuh tergantung dengan air. Dampak kekurangan air dalam tubuh dapat menyebabkan terjadinya dehidrasi, yaitu keadaan yang timbul karena tubuh kekurangan air sehingga tidak dapat menjalankan fungsi normalnya (Didinkaem, 2006).

Menurut Food and Nutrition Reseach 2002 dalam Proboprastowo dan Dwiriani (2004), kecukupan air tiap orang berbeda-beda dan berfluktuasi tiap waktu, lal tersebut dipengaruhi oleh beberapa faktor seperti jenis kelamin, usia, tingkat aktivitas serta faktor lingkungan. Tubuh yang berfungsi normal apabila mengalami kekurangan air, maka air yang hilang harus digantikan dengan mengkonsumsi makanan dan minuman yang mengandung air. Makanan biasanya meyumbang $20 \%$ dari jumlah total yang diperlukan, jadi bila mengkonsumsi dua liter air minum (delapan gelas) maka air yang hilang akan tergantikan. Rekomendasi harian Institute of Medicine menyarankan pria untuk mengkonsumsi tiga lt (13 gelas) dan perempuan mengkonsumsi 2,2 lt (9 gelas) dari total minuman dalam sehari, untuk menghindari terjadinya dehidrasi dan gangguan ginjal.

Dampak dari semakin sulitnya penyediaan air layak konsumsi serta moderisasi yang menuntut kepraktisan kebutuhan hidup menyebabkan pergeseran kebiasaan dan perilaku manusia. Perkembangan waktu serta pola hidup sehat menyebabkan semakin tingginya tingkat kesadaran masyarakat terhadap pola konsumsi air yang bermutu, sehat dan berkualitas maka masyarakat juga memerlukan hadirnya produk air minum yang layak dikonsumsi (Rahayu, 2008). Masyarakat saat ini telah beralih dari mengkonsumsi air minum biasa yang dimasak menjadi air minum dalam kemasan (AMDK). Menurut Hendro Baroena selaku Ketua Umum Aspadin, konsumsi AMDK berasal dari Pulau Jawa mencapai $40 \%$ sementara 60\% tersebar di luar Pulau Jawa. Proyeksi tingginya tingkat konsumsi AMDK di Indonesia berpengaruh terhadap volume penjualan.

Tabel 1.

Volume Penjualan AMDK di Indonesia Tahun 2009-2014

\begin{tabular}{cc}
\hline Tahun & Volume Penjualan (Miliar Liter) \\
\hline 2009 & 12,8 \\
2010 & 14,5 \\
2011 & 17,9 \\
2012 & 18,8 \\
2013 & 20,3 \\
2014 & 23,1 \\
\hline
\end{tabular}

Sumber : Aspadin 2014

Dapat dilihat pada Tabel 1, volume penjualan AMDK yang mengalami kenaikan signifikan, para produsen merek AMDK membuat variasi produk dengan di dukung strategi pemasaran yang baik untuk mengedukasi dan menarik perhatian konsumen. Persaingan yang bergitu ketat menuntut setiap perusahaan 
untuk berkreasi serta memunculkan pengembagan produk air minumnya melalui inovasi produk yang sesuai dengan kebutuhan konsumen agar terus mendapatkan kepercayaan dan mampu terus bersaing dalam pasar. Merek Aqua adalah pelopor bisnis AMDK dan saat ini menjadi produsen terbesar di Indonesia. Peluang inilah yang dilihat oleh PT. Amiro dalam menjalankan bisnis AMDK yang prospeknya menjanjikan serta menjalankan bisnis AMDK oleh PT Amiro tentu banyak yang harus diteliti untuk melihat apakah bisnis AMDK layak secara finansial atau tidak. Mengingat pentingnya kelayakan usaha bagi PT. Amiro pada usaha AMDK, maka hal ini mendasari penulis untuk mengkaji kelayakan usaha sebagai judul penelitian.

\subsection{Rumusan Masalah}

Rumusan Masalah penelitian ini adalah sebagai berikut.

1. Apakah usaha air minum dalam kemasan pada PT. Amiro secara finansial layak dilihat dari kriteria investasi yaitu NPV, IRR, Net B/C, Payback Period dan Analisis Sensitivitas?

2. Kendala-kendala apa saja yang dihadapi oleh PT. Amiro dalam menjalankan usaha?

\subsection{Tujuan Penelitian}

Tujuan penelitian ini adalah sebagai berikut.

1. Mengetahui usaha air minum dalam kemasan pada PT. Amiro layak secara finansial dilihat dari kriteria investasi yaitu NPV, IRR, Net B/C, Payback Perido dan Analisis Sensitivitas.

2. Mengetahui kendala-kendala yang dihadapi oleh PT. Amiro dalam menjalankan usaha.

\section{$2 \quad$ Metode Penelitian}

\subsection{Lokasi dan Waktu Penelitian}

Penelitian ini dilaksanakan di perusahaan AMDK PT. Amiro di Desa Uma Jero, Kecamatan Busungbiu, Kabupaten Buleleng. Penelitian dilakukan selama enam bulan pada bulan Januari - Juni 2018. Pemilihan lokasi penelitian secara purposive dengan pertimbangan bahwa perusahaan PT. Amiro merupakan salah satu perusahaan yang memproduksi air minum dalam kemasan dan mengijinkan peneliti melalukan studi kelayakan.

\subsection{Jenis dan Sumber Data}

Jenis data yang digunakan dalam penelitian adalah data kuantitatif dan kualitatif. Menurut Maulidi (2016) data kuantitatif adalah data informasi yang berupa simbol angka atau bilangan. Data kualitatif adalah informasi yang berbentuk kalimat verbal seperti identitas responden, struktur organisasi dan sejarah perusahaan. Sumber data penelitian ini berupa data primer dan data sekunder. Data primer meliputi data yang yang diperoleh melalui wawancara langsung dari sumber yang terdapat dilapangan, seperti biaya investasi dan biaya operasi. Data sekunder meliputi data yang diperoleh secara tidak langsung dari sumber yang terkait dengan penelitian, yaitu skripsi, jurnal, artikel online, dan buku yang mendukung selama proses penelitian dan penyusunan skripsi. 


\subsection{Metode Pengumpulan Data}

Pengumpulan data dalam penelitian ini dilakukan dengan field research yaitu dengan cara wawancara, dokumentasi, dan observasi sedangkan library research dilakukan dengan cara studi pustaka yang berkaitan dengan penelitian

\subsection{Informan Kunci}

Informan kunci adalah orang yang mengetahui dan memiliki berbagai informasi pokok yang diperlukan dalam penelitian. Penentuan informan kunci penelitian ini dipilih secara purposive. Informan kunci tersebut yakni I Ketut Hermawan sebagai Direktur Perusahaan AMDK PT. Amiro.

\subsection{Analisis Data}

Analisis yang digunakan dalam penelitian ini adalah analisis kuantitatif dan deskriptif. Analisis kuantitatif digunakan untuk menganalisis kelayakan usaha pada AMDK PT. Amiro dengan menggunakan kriteria investasi seperti NPV, IRR, Net B/C, Payback Period serta melakukan Analisis Sensitivitas dengan alat bantu software Microsoft Excel.

\section{Hasil dan Pembahasan}

\subsection{Net Present Value (NPV)}

Nilai bersih sekarang dihitung dengan menemukan perbedaan antara nilai arus manfaat saat ini dikurangi nilai arus biaya saat ini, atau hanya arus kas sekarang karena ini adalah ukuran arus kas diskon dari nilai proyek dan tingkat pengembalian internal (Sarma, 2010).

Tabel 2.

Hasil Kriteria Investasi AMDK PT. Amiro

\begin{tabular}{|c|c|c|}
\hline No & Kriteria Investasi & Nilai \\
\hline 1 & NPV & Rp. 12.640.670.205 \\
\hline 2 & IRR & $35,79 \%$ \\
\hline 3 & Net B/C & 3,64 \\
\hline
\end{tabular}

Berdasarkan Tabel 2, perhitungan Net Present Value (NPV) usaha AMDK PT. Amiro di Desa Uma Jero, Kecamatan Busungbiu, Kabupaten Buleleng dengan discount factor sebesar 13\% adalah Rp. 12.640.670.205. Hasil perhitungan ini menunjukkan bahwa usaha AMDK PT. Amiro layak untuk dilaksanakan karena NPV yang dihasilkan bernilai positif.

\subsection{Internal Rate of Return (IRR)}

Internal Rate of Return (IRR) adalah tingkat diskonto yang hanya membuat Net Present Value (NVP) arus kas sama dengan nol. Ukuran proyek yang paling berguna dan digunakan oleh hampir semua institusi termasuk Bank Dunia dalam analisis ekonomi dan keuangan proyek, ini mewakili rata-rata penghasilan dari uang yang digunakan dalam proyek selama masa proyek. (Sarma, 2010).

Berdasarkan Tabel 2, hasil perhitungan maka IRR sebesar 35,79\% dan lebih besar dari suku bunga yang berlaku yang berarti bahwa usaha ini akan 
memberikan keuntungan yang lebih besar dibandingkan dengan mendepositokan modal di bank dengan suku bunga yang berlaku, hal ini berarti bahwa proyek AMDK PT. Amiro layak untuk dilaksanakan karena nilai IRR lebih besar dari tingkat suku bunga yang berlaku saat ini yaitu $13 \%$.

\subsection{Net Benefit Cost Ratio (Net B/C)}

Net $\mathrm{B} / \mathrm{C}$ adalah perbandingan antara jumlah NPV positif dengan jumlah NPV negatif. Net B/C ini menunjukkan gambaran berapa kali lipat benefit akan diperoleh dari cost yang dikeluarkan (Choliq, 1999).

Berdasarkan Tabel 2, perhitungan Net B/C dengan discount factor 13\% adalah sebesar 3,64 yang berarti bahwa usaha AMDK PT. Amiro layak untuk dikembangkan karena nilai Net $\mathrm{B} / \mathrm{C}>1$. Nilai ini berarti bahwa setiap Rp. 1,00 yang dikeluarkan oleh perusahaan akan menghasilkan benefit (keuntungan) sebesar 3,64.

\subsection{Payback Period (PP)}

Menurut Dian Wijayanto (2012) Payback Period adalah periode yang diperlukan untuk menutup kembali pengeluaran investasi dengan cara nilai manfaat bersih yang terdapat di cashflow didiskontokan dan dikomulatifkan. Usaha AMDK PT. Amiro pada penelitian ini lamanya investasi kembali pada delapan tahun tiga bulan.

\subsection{Sensitivity Analysis (Analisis Sensitivitas)}

Analisis sensitivitas adalah suatu analisa untuk dapat melihat pengaruhpengaruh yang akan terjadi akibat keadaan yang berubah-ubah. Analisis sensitivitas dilakukan dengan mencari beberapa nilai pengganti pada komponen biaya dan manfaat yang masih memenuhi kriteria minimum kelayakan investasi atau maksimum nilai NPV sama dengan nol, nilai IRR sama dengan tingkat suku bunga dan $N e t \mathrm{~B} / \mathrm{C}$ ratio dengan 1 (cateris paribus). Analisis sensitivitas perlu dilakukan untuk melihat sampai berapa persen penurunan harga atau kenaikan biaya yang terjadi dapat mengakibatkan perubahan dalam kriteria kelayakan investasi dari menjadi tidak layak (Gittinger, 1986).

Analisis sensitivitas yang dilakukan pada usaha AMDK PT. Amiro dilihat dari peminjaman modal sebesar $47 \%$ dari investasi, kenaikan operasional sebesar $10 \%$ dan penurunan produksi sebesar $20 \%$. Analisis sensitivitas dilakukan untuk melihat apa yang akan terjadi dengan usaha AMDK PT. Amiro jika ada suatu kesalahan atau perubahan dalam dasar perhitungan biaya dan manfaat. 
Tabel 3.

Nilai Kriteria Investasi Usaha AMDK PT. Amiro dengan Dua Macam Analisis Sensitivitas.

\begin{tabular}{lcccc}
\hline No & $\begin{array}{c}\text { Kriteria } \\
\text { Investasi }\end{array}$ & $\begin{array}{c}\text { Pinjaman di Bank } \\
\text { sebesar 47\% dari } \\
\text { Biaya Investasi }\end{array}$ & $\begin{array}{c}\text { Kenaikan } \\
\text { Operasional 10\% }\end{array}$ & $\begin{array}{c}\text { Penurunan Produksi } \\
20 \%\end{array}$ \\
\hline 1 & NPV & Rp. 12.640.670.205 & Rp. 4.966.480.802 & Rp. 10.357.897.464 \\
2 & IRR & $41 \%$ & $26,11 \%$ & $31 \%$ \\
3 & Net B/C & 5,03 & 2,53 & 3,51 \\
\hline
\end{tabular}

Sumber : Data diolah (2018)

Berdasarkan Tabel 3, dapat disimpulkan bahwa setiap skenario usaha AMDK PT. Amiro layak untuk dilaksanakan, hal tersebut diketahui dengan melihat nilai kriteria kelayakan investasi skenario I, II dan III yang sesuai dengan syarat kelayakan investasi. Syarat kelayakan investasi ialah nilai NPV usaha AMDK PT. Amiro pada skenario I, II dan III dari Rp 0, IRR lebih dari discount rate yang ditentukan yaitu $13 \%$ dan Net B/C lebih dari Rp. 1,00.

Nilai NPV pada kriteria kelayakan investasi memiliki arti bahwa usaha AMDK PT. Amiro memberikan keuntungan dengan nilai sekarang (present value) selama umur proyek yaitu 20 tahun. Nilai sekarang didapatkan dari perkalian manfaat bersih dengan discount factor yang menggunakan discount rate sebesar 13\%. Pada skenario I, II dan III akan memiliki keuntungan dengan nilai sekarang sebesar Rp. 12.640.670.205, Rp. 4.966.480.802, dan Rp. 10.357.897.464 selama 20 tahun usaha berjalan. Nilai NPV tersebut dinyatakan layak karena memiliki nilai lebih dari nol.

IRR merupakan nilai tingkat pengembalian modal atas biaya investasi yang dikeluarkan dalam memulai usaha AMDK PT. Amiro. Usaha AMDK PT. Amiro dinyatakan layak jika nilai IRR lebih besar dari discount rate. Discount rate yang digunakan pada analisis kelayakan investasi ini ialah sebesar $13 \%$. Angka tersebut berdasarkan suku bunga Bank BRI. Nilai IRR dari ketiga skenario melebihi nilai discount rate mengambarkan bahwa mengeluarkan uang untuk investasi di usaha AMDK PT. Amiro lebih mengguntungkan sebesar $41 \%$ pada skenario I, 26,11\% pada skenario II pada skenario III sebesar 31\% dari pada diinvestasikan di Bank BRI yang hanya mendapatkan keuntungan 13\% dari biaya investasi yang dikeluarkan.

Kriteria kelayakan investasi ketiga adalah Net B/C yang memilki arti perbandingan antara manfaat bersih dengan biaya yang dikeluarkan. Net B/C yang dinyatakan layak apabila memiliki nilai lebih dari satu yang berarti manfaat bersih yang didapatkan lebih dari jumlah biaya yang dikeluarkan. Nilai Net B/C pada skenario I, II dan III dengan tingkat diskonto $13 \%$ adalah 5,03 2,53 dan 3,51. Interpretasi dari Net B/C skenario I, II dan III yaitu setiap pengeluaran Rp 1 akan mendapatkan manfaat bersih sebesar Rp. 5.05, Rp. 2.53 dan Rp. 3.51.

Berdasarkan hal tersebut, dapat disumpulkan bahwa usaha AMDK PT. Amiro sensitif pada kondisi biaya operasional naik sebesar $10 \%$ karena nilai NPV lebih kecil dari opportunity cost of capital, tetapi nilai IRR masih lebih besar dari discount rate yang telah ditetapkan sebesar $13 \%$ dan Net $\mathrm{B} / \mathrm{C}$ lebih besar dari satu sehingga usaha AMDK PT. Amiro layak untuk dilaksanakan, sedangkan pada 
kondisi penurunan produksi sebesar $20 \%$ tidak sensitif apabila terjadi penurunan produksi.

\subsection{Kendala-kendala yang Dihadapi dalam Menjalankan Usaha AMDK PT.Amiro}

Berdasarkan hasil penelitian terkait kendala-kendala dalam studi kelayakan investasi usaha AMDK PT. Amiro menurut Hermawan (2018) menyatakan bahwa dalam membangun usaha ini, proses pengurusan perijinan memerlukan banyak waktu untuk memenuhi persyaratan yang diperlukan dalam mendapatkan ijin usaha. Usaha AMDK PT. Amiro hingga saat ini masih dalam tahap menunggu pendaftaran nama perusahaan ke Badan POM Pusat. Ijin usaha ini diperlukan sebagai legalitas sehingga mencegah terjadinya hal - hal yang tidak diinginkan seperti masalah hokum, untuk mengatasi kendala-kendala yang muncul dikemudian hari terkait perijinan, hal yang dapat dilakukan PT. Amiro dengan mendatangi konsultan yang memiliki keahlian dalam menyelesaikan masalah perijinan yang memerlukan waktu lama tetapi hal ini juga menimbulkan biaya tambahan untuk membayar jasa dalam mengurusi perijinan usaha AMDK PT. Amiro.

Bisnis AMDK memiliki beberapa pesaing besar yang sudah menguasai pasar seperti Aqua, Prima, Club, Cleo, Le Minerale sehingga PT. Amiro memerlukan survei pasar untuk milihat prospek pasar yang bisa didapatkan. PT. Amiro merupakan perusahaan baru dalam usaha AMDK dan belum dikenal oleh masyarakat sehingga memerlukan strategi untuk mendapatkan market share dari pasar yang sudah sangat padat. PT. Amiro harus membidik pasar-pasar yang sementara ini belum tersentuh, misalkan daerah yang sebagian populasinya masih belum menggunakan air mineral karena pada zaman dulu orang tidak minum air minum dalam kemasan tetapi minum air yang direbus, di masa sekarang semua mengkonsumsi air minum dalam kemasan. Potensi inilah yang harus dilihat oleh PT. Amiro dalam memperoleh market share pasar dan PT. Amiro harus selalu mempertahankan kualitas produk dan label yang digunakan agar konsumen mudah mengingat produk dan dapat meningkatkan pemasaran PT. Amiro, karena dengan mempertahankan kualitas produk dan label yang digunakan dapat menentukan masa depan perusahaan dan disisi lain konsumen dapat melihat konsistensi perusahaan.

\section{Simpulan dan Saran}

4.1 Simpulan

Berdasarkan hasil penelitian yang dilakukan, dapat disumpulkan bahwa analisis kelayakan usaha AMDK PT. Amiro di Desa Uma Jero, Kecamatan Busungbiu, Kabupaten Buleleng layak untuk dikembangkan dan ditinjau dari beberapa aspek yaitu sebagai berikut.

1. Berdasarkan penelitian usaha AMDK PT. Amiro dilihat dari nilai NPV sebesar Rp.12.640.670.205, IRR lebih besar dari discount rate yaitu sebesar 35,79\% dan Net B/C sebesar 3,64 dan Payback Period selama 8 tahun 3 bulan maka secara finansial usaha AMDK PT. Amiro layak untuk dilaksanakan.

2. Berdasarkan hasil penelitian terkait kendala-kendala dalam studi kelayakan investasi usaha AMDK PT. Amiro, bahwa dalam membangun 
usaha ini proses pengurusan perijinan memerlukan banyak waktu untuk memenuhi persyaratan yang diperlukan dalam mendapatkan ijin usaha. Usaha AMDK PT. Amiro hingga saat ini masih dalam tahap menunggu pendaftaran nama usaha ke Badan POM Pusat sehingga memperlancar jalannya usaha. PT. Amiro merupakan pemain baru dalam usaha AMDK sehingga belum dikenal oleh masyarakat sehingga memerlukan strategi guna mendapatkan market share dari pasar yang sudah sangat padat.

\subsection{Saran}

Berdasarkan penelitian yang dilakukan, adapun saran yang diajukan penulis sebagai berikut:

1. Perusahaan PT. Amiro dalam menjalankan bisnis AMDK, yang paling penting bukan hanya kualitas produk, tapi juga harus melakukan distribusi dan produknya harus selalu ada. PT. Amiro harus membidik pasar-pasar yang sementara ini belum tersentuh, misalnya daerah yang sebagian populasinya masih belum menggunakan air mineral, itu merupakan potensi di mana PT. Amiro bisa masuk mendapatkan market share pasar.

2. PT. Amiro harus melakukan investasi dalam pemanfaatan kemajuan teknologi informasi dan komunikasi yang saat ini terus berkembang, ini berguna memperluas pengenalan (promosi) produk maupun penjualan produk. Pemanfaatan teknologi ini dapat dilakukan dengan menggunakan media sosial yang banyak digunakan oleh masyarakat, yaitu facebook dan instagram. Media sosial tersebut memiliki pengguna yang paling banyak dan tidak membutuhkan biaya besar. PT. Amiro juga bisa membuat website untuk memudahkan konsumen melihat profil perusahaan dari produk hingga layanan konsumen.

\section{Ucapan Terimakasih}

Penulis mengucapkan terimakasih kepada I Ketut Hermawan selaku pemilik perusahaan yang telah memberikan ijin dan kemudahan selama proses penelitian berlangsung.

\section{Daftar Pustaka}

Aspadin. 2014. Volume Penjualan AMDK di Indonesia. Asosiasi Perusahaan Air Minum Dalam Kemasan Indonesia. https://industri.kontan.co.id/news/penjualan-air-minum-kemasan-tetapsegar. Diunduh pada 25 November 2017.

Choliq, Abdul., Wirasamita, Rivai., dan Hasan, Sumarna. 1999. Evaluasi Proyek. Edisi Revisi. Pionir Jaya. Bandung.

Didinkaem. 2006. Berapa Banyak Harus Minum Setiap Harinya. http://www.halalguide.info/content/view. Diakses tanggal 22 November 20017. 
Gittinger, J. P. 1986. Analisis Ekonomi Proyek - Proyek Pertanian. Edisi Kedua. UI Press. Jakarta.

Hardinsyah el al. 2011. Air Bagi Kesehatan. Centra Communications. Jakarta.

Maulidi, Achmad. 2016. Data Kuantitatif dan Data Kualitatif. http://www.kanalinfo.web.id. Diunduh pada 25 November 2017.

Proboprastowo S.M dan Dwiriani C.M. 2004. Angka Kecukupan Air dan

Elektrolit. Lembaga Ilmu Pengetahun Indonesia. Jakarta.

Rahayu A. 2008. Deteksi Adanya Bakteri Pada Air Minum dalam Kemasan Galon. Jurnal Kedokteran Universitas Wijaya Kusuma. Surabaya.

Sarma, A.K. 2010. Methods/Criteria of Project Evaluation or Measures of project Worth of Investment. Professor Agril Economics. FA. AAU Jorhat. https://images.template.net/wpcontent/uploads/2016/07/26100327/ProjectEvaluation-Methods-Template.pdf. Diunduh pada 20 November 2017.

Wijayanto, Dian. 2012. Pengantar Manajemen. PT Gramedia Pustaka Utama. Jakarta. 